\title{
SALVAR LA CIENCIA
}

Daniel Sarewitz*

T a ciencia, el orgullo de la modernidad, nuestra única fuente de Lconocimiento objetivo, está en graves problemas. Auspiciados por cincuenta años de creciente inversión pública, los científicos son más productivos que nunca y vierten millones de artículos en miles de publicaciones que cubren una gama cada vez mayor de campos y fenómenos. Pero gran parte de este supuesto conocimiento es debatible, poco confiable, inutilizable o erróneo. De la metástasis del cáncer al cambio climático y de la economía del crecimiento a las pautas dietéticas, la ciencia -que supuestamente aporta claridad y soluciones- hoy genera contradicción, controversia y confusión. En este camino también se está socavando la idea, que ha perdurado unos cuatrocientos años, de que la acción humana prudente se puede basar en verdades verificables de manera independiente. La ciencia está atrapada en un vórtice autodestructivo; para escapar, tendrá que abdicar a su protegido estatus político, y reconocer sus límites y su responsabilidad con el resto de sociedad.

Es difícil desentrañar la historia de cómo se llegó a esta situación, debido no en poca medida a que la empresa científica está bien defendida por muros de publicidad exagerada, mito y negación. Aunque gran parte del problema se remonta a una mentira descarada pero hermosa que sustenta el poder político y cultural de la ciencia. Una

* Profesor de Ciencia y Sociedad en la Escuela para el Futuro de la Innovación y la Sociedad de la Universidad Estatal de Arizona, codirector del Consortium for Science, Policy, and Outcomes de dicha universidad, [daniel.sarewitz@asu.edu]. Este escrito, que apareció en The New Atlantis 49, 2016, pp. 5-40, se publica con las autorizaciones correspondientes. Traducción de Alberto Supelano. Fecha de recepción: 05-11-2016, fecha de aceptación: 04-09-2017. Sugerencia de citación: Sarewitz, D. (2017). Salvar la ciencia, Revista de Economía Institucional 19(37), 31-65. Dor: http://dx.doi.org/10.18601/01245996.v19n37.03 
mentira expresada de la manera más convincente justo cuando Estados Unidos emprendía un largo periodo de extraordinario crecimiento, científico, tecnológico y económico. Dice así:

El progreso científico en un frente amplio es resultado del libre juego de intelectos libres, que trabajan en temas de su propia elección del modo que dicta su curiosidad por la exploración y lo desconocido.

Esta convincente visión de la ciencia, tan profundamente arraigada en nuestra psique cultural que parece un eco del sentido común, proviene de Vannebar Bush, el ingeniero del mit que fue el arquitecto de la empresa de investigación de la nación en la Segunda Guerra Mundial, que produjo la bomba atómica y ayudó a avanzar en el radar de microondas, la producción en masa de antibióticos y otras tecnologías esenciales para la victoria de los aliados. En ese proceso se hizo famoso. Apareció en la portada de Time, y fue apodado el "general de la Física”. Cuando la guerra se acercaba a su fin, Bush percibió la transición de la ciencia estadounidense a una nueva era de paz, en la que los mejores científicos académicos seguirían recibiendo la abundante financiación del gobierno a la que se habían acostumbrado desde Pearl Harbor, pero ya no estarían atados a los estrechos dictados de la necesidad y la aplicación militar, para no mencionar la disciplina y el secreto. En cambio, como expresó en su informe de julio de 1945, Ciencia, la frontera sin fin, los científicos sentarán los fundamentos de "nuevos productos y nuevos procesos" para dar salud, pleno empleo y seguridad militar a la nación prosiguiendo la "investigación en los dominios más puros de la ciencia”.

Desde esta perspectiva, la mentira que Bush contó era quizá menos un esfuerzo consciente de engañar que una manipulación seductora, con fines políticos, de creencias muy extendidas sobre la pureza de la ciencia. De hecho, sus esfuerzos para crear las condiciones de una generosa inversión de largo plazo en la ciencia tuvieron sumo éxito, y la financiación federal para "investigación básica" pasó de 265 millones de dólares en 1953 a 38 mil millones en 2012, una suma veinte veces mayor cuando se ajusta por la inflación. Más impresionante aún fue el incremento para investigación básica en las universidades, que pasó de 82 millones de dólares a 24 mil millones, una suma más de cuarenta veces mayor cuando se ajusta por la inflación. En cambio, el gasto del gobierno en más "investigación aplicada" en las universidades fue mucho menos generoso, solo llegó a algo menos de 10 mil millones. El poder de la mentira era palpable: "el libre juego de intelectos libres" proporcionaría el conocimiento que la nación necesitaba para afrontar los retos del futuro. 
Junto con todo ese dinero, la hermosa mentira proporcionó una brillante justificación política del gasto público con poca responsabilidad pública. Los políticos daban fondos de los contribuyentes a los científicos, y solo los científicos podían evaluar la investigación que hacían. Los esfuerzos externos para guiar el curso de la ciencia solo interferían en su avance libre e impredecible.

Los frutos de la exploración científica guiada por la curiosidad hacia lo desconocido a menudo han sido magníficos. El reciente descubrimiento de las ondas gravitacionales -una confirmación experimental de la obra teórica de Einstein de un siglo antes- fue una culminación muy publicitada de miles de millones de dólares de gasto público y de décadas de investigación realizada por grandes equipos de científicos. Las multimillonarias inversiones en exploración espacial también han producido un conocimiento similarmente sorprendente de nuestro sistema solar, como las pruebas recientes de agua corriente en Marte. Y, hablando de cosas sorprendentes, antropólogos y genetistas usaron técnicas de secuenciación del genoma para probar que los primeros humanos se cruzaron con otras dos especies de homínidos, los de Neandertal y los de Denísova. Tales descubrimientos aumentan nuestra admiración por el universo y por nosotros mismos.

Y, de algún modo, al parecer, a medida que la curiosidad científica alienta una mayor comprensión del funcionamiento esencial de nuestro mundo, la ciencia ha logrado a la vez entregar una cornucopia de milagros en el lado práctico de la ecuación, tal como Bush predijo: computadores digitales, aviones jet, celulares, Internet, láseres, satélites, GPs, imágenes digitales, energía nuclear y solar. Cuando Bush escribió su informe, nada hecho por humanos orbitaba alrededor de la Tierra, el software no existía y la viruela subsistía.

Se podría perdonar entonces que se crea que esta asombrosa profusión de cambio tecnológico fue producto del "libre juego de intelectos libres, que trabajan en temas de su propia elección del modo que dicta su curiosidad por la exploración y lo desconocido". Pero sería muy equivocado.

La ciencia ha sido importante para el desarrollo tecnológico, por supuesto. Los científicos descubrieron y probaron fenómenos que resultaron tener aplicaciones tecnológicas muy amplias. Pero los milagros de la modernidad de la lista anterior no provinieron del "libre juego de intelectos libres", sino de la subordinación de la creatividad científica a las necesidades tecnológicas del Departamento de Defensa de Estados Unidos (DD). 
La historia del modo en que el DD movilizó la ciencia para ayudar a crear a nuestro mundo pone al desnudo la mentira y ofrece tres lecciones difíciles que se han de aprender para que la ciencia evada la calamidad que hoy enfrenta.

Primera, el conocimiento científico avanza con más rapidez, y es más valioso para la sociedad, no cuando su curso es determinado por el libre juego de "intelectos libres" sino cuando se dirige a resolver problemas, en especial los relacionados con la innovación tecnológica. Segunda, cuando la ciencia no se dirige a resolver esos problemas, tiende a ir a tientas, por vías que pueden ser muy perjudiciales para ella misma. Tercera -y esta es la lección más difícil y más temible-, la ciencia será más confiable y más valiosa para la sociedad actual no por estar protegida de las influencias sociales sino por ser conducida, en forma cuidadosa y apropiada, a una relación directa, abierta e íntima con esas influencias.

\section{CÓMO DIO EL DD SU ENCANTO A LA CIENCIA}

Muy poco después de la Segunda Guerra Mundial, el Departamento de Guerra -al que muy pronto se llamó Departamento de Defensaempezó a reunir a todo el conjunto de actores necesarios para asegurar que Estados Unidos tuviera las tecnologías necesarias para ganar la Guerra Fría. Eso es lo que el presidente Eisenhower llamaría, en 1961, "complejo militar-industrial" y lo que hoy se denominaría, en forma más amplia, "sistema nacional de innovación”. Este incluye científicos y laboratorios universitarios, pequeñas y grandes empresas que desarrollan y comercializan innovaciones, y usuarios de esas innovaciones; en este caso, el ejército. El DD pudo catalizar la rápida innovación porque el dinero no era un problema; la misión -asegurar que la tecnología militar estadounidense fuera mejor que la de los demás- era lo único que importaba.

¿Cómo se crean materiales para motores jet y fuselajes más ligeros y durables en condiciones extremas? ¿Cómo se obtienen imágenes de alta resolución de las instalaciones militares enemigas desde un satélite en órbita? ¿Cómo se asegura que los enlaces de comunicación militar puedan funcionar después de una guerra nuclear? Este es el tipo de preguntas que el ejército necesitaba responder, preguntas que exigían avances en el conocimiento fundamental así como en el conocimiento tecnológico. E1 DD no solo proporcionaba inversiones sino también un potente enfoque para el avance en investigación básica en campos que iban de la física de altas energías a la ciencia de materiales, la dinámica de fluidos y la biología molecular. 
Al mismo tiempo, protegido de la lógica del mercado y de los caprichos de la política por el imperativo de la defensa nacional, el DD era un cliente exigente de algunos de los productos tecnológicos más avanzados que podían producir las empresas de alta tecnología. Por ejemplo, el primer computador digital -construido a mediados de los años cuarenta para calcular las trayectorias de las piezas de artillería y usado para diseñar la primera bomba de hidrógeno- costó cerca de 500 mil dólares (unos 4,7 millones de hoy), funcionaba miles de millones de veces menos rápido que los computadores actuales, ocupaba el espacio de un microbús y no tenía aplicación comercial inmediata. ¿Quién excepto el Pentágono compraría algo tan alocado? Pero el DD también apoyó la ciencia necesaria para mantener en marcha la innovación. A finales de los años cincuenta y bien entrados los sesenta, mientras crecía el papel de los computadores en asuntos militares pero la ciencia no mantenía el paso, la Agencia de Proyectos de Investigación Avanzada del DD creó en esencia la informática como disciplina académica financiando el trabajo en Miт, Carnegie Mellon, Stanford y otras instituciones.

Otro ejemplo: en los años cuarenta, los primeros motores jet se debían reparar cada cien horas y eran cuarenta y cinco veces menos eficientes en combustible que los motores de pistón. ¿Por qué despilfarrar dinero público en esa tecnología? Porque los planificadores militares sabían que la potencia del jet prometía un rendimiento en combate muy superior al de los aviones con motores de pistón. Durante décadas la fuerza aérea y la marina financiaron la investigación y el desarrollo de la industria aeronáutica para mejorar continuamente los motores jet. Entretanto, la compañía Boeing podía tomar el tanque de combustible aéreo impulsado por motores jet que desarrollaba para la fuerza aérea y usar un diseño similar para su jet de pasajeros 707, el primer avión comercial seguro y confiable.

Y otro más: AT\&T y Bell Labs, donde se descubrió el efecto transistor, podían usar la demanda -y las inversiones- del Cuerpo de Comunicaciones del Ejército de tecnologías de comunicación más pequeñas y más confiables en el campo de batalla para mejorar la comprensión científica de los materiales semiconductores así como la confiabilidad y el desempeño de los transistores. Las compras militares mantuvieron a flote las nuevas industrias de transistores, semiconductores y circuitos integrados a comienzos y mediados de los años cincuenta. Como explicó el historiador Thomas Misa en su estudio del papel del DD para estimular el desarrollo de transistores: "Al subsidiar el desarrollo del diseño y la construcción de fábricas 
[...] el ejército catalizó el establecimiento de una base industrial”, y así ayudó a crear la columna vertebral tecnológica e industrial para la era de la información. Las nuevas armas -como los sistemas de misiles y las ojivas nucleares cada vez más potentes- siguieron impulsando el desarrollo y la demanda de componentes electrónicos más y más sofisticados y confiables, como los microprocesadores y los supercomputadores.

Hoy, el DD sigue impulsando la innovación rápida en áreas escogidas, incluida la robótica (en especial para la guerra de drones) y el mejoramiento humano (p. ej., para mejorar el desempeño de los soldados en el campo de batalla). Aunque la creatividad y la productividad del Pentágono como innovador se han disipado notablemente debido a una combinación de diversos factores, incluidos el crecimiento burocrático excesivo, la interferencia del Congreso y el compromiso de largo plazo con sistemas de armamento muy costosos y problemáticos con poco potencial civil, como la defensa antimisiles y el avión de caza F-35.

Pero los fundamentos científicos y tecnológicos que el DD ayudó a crear durante la Guerra Fría siguen apoyando la economía americana. Para tomar solo un ejemplo, de las trece áreas de avance tecnológico que fueron esenciales para desarrollar los iPhone, once -incluidos el microprocesador, el GPS e Internet- se remontan a vitales inversiones militares en investigación y desarrollo tecnológico.

Los estadounidenses ensalzan al científico como un genio con la cabeza en las nubes (el héroe Einstein) y al inventor como un genio inadaptado metido en un garaje (el héroe Steve Jobs o Bill Gates). Pero la desconcertante realidad es que gran parte del mundo tecnológico actual existe debido al papel del DD como catalizador y orientador de la ciencia y la tecnología. Esa era la política industrial, y funcionó porque reunió a todos los actores en el juego de la innovación, los disciplinó, les proporcionó un enfoque estratégico de largo plazo para sus actividades y los protegió de la racionalidad del mercado, la cual habría condenado casi todas las ideas alocadas y muy costosas que hoy hacen girar el mundo. Los grandes logros del complejo militarindustrial no obedecen a que dejara que los científicos exploraran "temas de su propia elección del modo que dicta su curiosidad", sino a que canalizó esa curiosidad hacia la solución de problemas que el DD quería resolver.

Se supone que tales políticas industriales guiadas por objetivos son cosa de los planes quinquenales soviéticos, no de las democracias de mercado, y ni los científicos ni los encargados de política están dis- 
puestos a reconocer el rol del DD en la creación de los fundamentos de nuestra economía y nuestra sociedad actuales. La hermosa mentira de Vannevar Bush es una explicación ideológica y política mucho más atractiva. Pero no todo el mundo ha sido engañado.

\section{GUERRA CONTRA EL CÁNCER}

A Fran Visco le diagnosticaron cáncer de mama en 1987. Abogada litigante de Filadelfia a quien nadie intimidaba, eligió ser tratada con una quimioterapia menos tóxica que la que le recomendó su médico. También empezó a ser voluntaria en un grupo local de apoyo a pacientes con cáncer de mama, por lo que fue invitada a la reunión organizadora de lo que se llamó Coalición Nacional contra el Cáncer de Mama (NBCC). La NBCC fue concebida como una organización que daría una voz unificada a los grupos locales de pacientes de todo el país, un enfoque atractivo para su temperamento activista. Visco fue primer presidente de la organización, y desde entonces ha sido líder nacional en la movilización de la ciencia, la medicina, la política y los políticos en torno al objetivo de eliminar la enfermedad.

Visco era hija de la mentira. "Todo lo que sabía de ciencia era que consistía en una búsqueda pura de la verdad y el conocimiento”. Lógicamente, ella y los demás activistas de la NBCC empezaron tratando de obtener más dinero para investigar el cáncer de mama en la organización de investigación más elogiada del país, el Instituto Nacional del Cáncer de los Institutos Nacionales de Salud (INs). Pero Visco era también hija de los años sesenta, inclinada a cuestionar la autoridad, y quería tener un papel activo en el cálculo del dinero necesario para investigación y la mejor manera de gastarlo. Ella y sus colegas de la NBCC identificaron una comunidad de investigadores que consideraron particularmente innovadora, y la reunieron en febrero de 1992 para discutir qué se necesitaba para encontrar curas más rápidamente y cuánto costarían. En conjunto, los defensores y los científicos determinaron que la comunidad científica podría absorber y emplear bien 300 millones de dólares nuevos, una meta que encontró fuerte apoyo en el Congreso. Entretanto, Visco y otros defensores de pacientes empezaron a sumergirse profundamente en la ciencia para "sentarse en la mesa y averiguar cómo se debían gastar esos dólares”.

Por un accidente en la elaboración del presupuesto, la única manera de lograr la meta de 300 millones de dólares era asignar la mayor parte del dinero al DD. Por ello, en noviembre de 1992 el Congreso asignó 210 millones de dólares a un programa de investigación del cáncer de mama que sería administrado por el ejército. El plan inicial era 
transferir la mayor parte del dinero al Instituto Nacional del Cáncer (INC), pero cuando Visco y sus colegas de la NBCC se reunieron con funcionarios del INC para discutir cómo gastar mejor los nuevos dólares, el director Sam Broder explicó cuán difícil era impulsar la ciencia porque las prioridades eran fijadas de abajo hacia arriba por los intereses de la comunidad de investigación. Esto, dijo Visco, "no nos garantizaba que él haría algo diferente".

Cuando Visco fue al DD, "la reunión fue totalmente diferente". Con el mayor general Richard Travis, director de investigación y desarrollo del ejército, "fue: 'como sabe, somos el ejército, y si nos da una misión, averiguamos cómo cumplir esa misión. Ladies, voy a conducirlas en la batalla y vamos a ganar la guerra".

Aunque al inicio a Visco le "aterraba" trabajar con el ejército, también lo encontró refrescante y potenciador, una "colaboración y una asociación fantásticas". Los dirigentes del INC le recordaron que era una activista y una paciente, no un par. Pero el general Travis les dijo a ella y a sus colegas: "Ustedes quieren sentarse en la mesa, me aseguraré de que tengan un asiento". El ejército acogió la participación de pacientes-activistas en la planeación del programa de cáncer de mama, las involucró en la selección final de los proyectos científicos que se financiarían e incluso en la revisión de los méritos de las diversas propuestas de investigación.

El enfoque del DD, su entusiasmo por asociarse con defensorespacientes y su dedicación a resolver el problema del cáncer de mama -y no solo a mejorar nuestra comprensión científica de la enfermedad-atrajeron aún más a Visco. Los beneficios no tardaron mucho en aparecer. Durante la primera ronda de donaciones en 1993-1994, el programa financió la investigación de una nueva terapia biológica, un proyecto rechazado varias veces por el sistema de revisión por pares del Ins porque la visión convencional era que ese tipo de terapias no funcionaría. Los estudios financiados por el DD llevaron al desarrollo del Herceptín, uno de los avances más importantes en el tratamiento del cáncer de mama en las últimas décadas.

De acuerdo con Dennis Slamon, director científico de ese proyecto, la apertura del programa del DD para financiar proyectos como el suyo, que iba contra las creencias científicas predominantes, se debía a los pacientes-activistas. "Absoluta e inequívocamente, sin duda. La comunidad científica, quizá incluso yo mismo, era escéptica de que fuera factible que un montón de legos, sin profunda formación científica, se sentara a la mesa y participara en el proceso de revisión 
por pares de manera significativa. $\mathrm{Y}$ no podíamos haber estado más equivocados".

Ha habido pocos avances en el tratamiento del cáncer de mama desde entonces, pero uno de los más promisorios - una terapia personalizada llamada palbociclib- fue financiado por el mismo programa del DD y fue aprobado por la FDA en 2015, después de ensayos clínicos exitosos. A pesar de las objeciones de los científicos que asesoran el programa, los pacientes-defensores también presionaron al DD para que aumentara la financiación de enfoques inmunológicos para la cura del cáncer de mama, incluido el apoyo a la investigación de vacunas nada convencionales para que sea respaldada por el Inc o la industria farmacéutica.

La colaboración de la NBCC con el DD ilustra cómo se puede guiar la ciencia en direcciones que no se seguirían si se dejara únicamente en manos de científicos. Pero eso no resultó suficiente. Veinte años después del programa de cáncer de mama del ejército, Visco sintió gran frustración. El ejército estaba subsidiando propuestas innovadoras de alto riesgo que no podían haber sido financiadas por el Inc. Pero allí terminó la influencia del programa. Lo que Visco y el general Travis no habían apreciado era que, cuando se trataba del cáncer de mama, el programa carecía del ingrediente clave que hizo del DD un innovador tan exitoso en otros campos: el dinero y el control necesarios para coordinar a todos los actores del sistema de innovación y responsabilizarlos para que trabajaran hacia un objetivo común. Por ello, a medida que la NBCC y otros grupos captaban cada vez más dinero del sistema de investigación mediante campañas de cabildeo efectivas, para Visco era cada vez más claro que los principales beneficiarios eran los científicos atraídos por la nueva financiación, no los pacientes de cáncer de mama. Sin duda, el apoyo del DD a la investigación innovadora es "mejor que lo que está ocurriendo en el INC y en el INs, pero no bastante mejor [...] es innovación dentro del sistema existente".

En últimas, "todo el dinero que se dedicó al cáncer de mama creó más problemas que éxitos", dice Visco. Lo que parecía impulsar a muchos científicos era el deseo de "aparecer en la portada del New York Times", no el de averiguar cómo acabar con el cáncer de mama. A ella le parecía que la creatividad se ahogaba cuando los investigadores mostraban "un efecto de rata de campo", ir a la caza de abundantes dólares para investigación y saltar rápidamente de un tema candente, pero al final infructuoso, a otro. "Nos cansamos de ver a tanta gente hacer carrera en torno a un gen o una proteína", 
dice ella. Visco comprende como un científico la extraordinaria complejidad del cáncer de mama y las dificultades para avanzar hacia una cura. Pero cuando llegó al punto en que la NBCC había ayudado a captar 2 mil millones de dólares del programa del DD, se empezó a preguntar: “¿Y qué? ¿Qué hay para mostrar? ¿Se quiere hacer esta ciencia y quê?".

"En algún momento se debe salvar realmente una vida", dice Visco.

\section{LA MEDIDA DEL PROGRESO}

Durante gran parte de la historia humana, la tecnología avanzó mediante la artesanía y el aprendizaje por ensayo y error, con poca comprensión teórica. El estudio sistemático de la naturaleza-lo que hoy llamamos ciencia- era un dominio distinto, que poco o nada contribuía al desarrollo tecnológico. No obstante, durante siglos la tecnología contribuyó de manera obvia al avance científico puesto que instrumentos prácticos tales como lentes, brújulas y relojes hicieron posible que los científicos estudiaran la naturaleza con exactitud y resolución cada vez mayores. La relación solo empezó a oscilar en ambos sentidos - la ciencia a contribuir al avance tecnológico y a la vez beneficiarse de este avance- en el siglo xix cuando, por ejemplo, surgió la química orgánica y encontró aplicación en la industria alemana de tinturas.

Y cuando la Revolución Industrial vinculó la innovación tecnológica a un crecimiento económico sin precedentes históricos, los científicos empezaron a hacer muchas contribuciones importantes al conocimiento fundamental, estudiando fenómenos cuya existencia era sacada a la luz debido a las nuevas tecnologías de un mundo industrializado. Los esfuerzos para mejorar el rendimiento de las máquinas de vapor, de la fabricación de vino y de acero, y de la comunicación telefónica - para mencionar solo unos pocos- orientaron buena parte de la investigación científica y, en algunos casos, impulsaron campos de investigación básica totalmente nuevos, como la termodinámica, la bacteriología y la radioastronomía. Las nuevas tecnologías también fomentaron la disciplina y el enfoque en áreas de la ciencia básica que avanzaban con lentitud, como hicieron las vacunas en la inmunología y los aviones en la aerodinámica teórica.

La ciencia ha sido un empeño tan exitoso en los últimos doscientos años debido en gran parte a que la tecnología le abrió nuevos caminos. Las nuevas tecnologías no solo crearon nuevos mundos, nuevos fenómenos y nuevas preguntas que debe explorar la ciencia, sino que los resultados tecnológicos demuestran en forma continua e inequívoca 
la validez de la ciencia que se hace. La industria electrónica y la física de semiconductores avanzaron mano a mano no porque los científicos, trabajando "del modo que dicta su curiosidad por la exploración y lo desconocido", siguieran lanzando sobre las paredes de los laboratorios nuevos descubrimientos que luego hicieron avanzar la tecnología de los transistores, sino porque la búsqueda para mejorar continuamente el desempeño tecnológico planteó nuevas preguntas científicas y exigió avanzar en nuestra comprensión del comportamiento de los electrones en diferentes tipos de materiales.

O, de nuevo, consideremos cómo se inició el rápido desarrollo de los computadores en los años cincuenta, catalizado por el DD y guiado por la demanda de nuevos tipos de teorías y de conocimientos sobre cómo adquirir, almacenar y procesar información digital; de una nueva ciencia para una nueva tecnología. Treinta años después, los investigadores en computación investigaban fenómenos en un campo de rápido desarrollo tecnológico que antes no existía -el ciberespacio y la World Wide Web- y se hacían preguntas que nunca antes se habrían imaginado, y mucho menos respondido. La Fundación $\mathrm{Na}$ cional de Ciencias financió investigación básica en este nuevo campo, incluidas las becas a dos estudiantes de posgrado en informática de la Universidad de Stanford que querían entender cómo navegar mejor en el paisaje novedoso y en expansión de la información digital. Ellos publicaron sus resultados en 1998, en un artículo titulado "La anatomía de un gran motor de búsqueda hipertextual a gran escala en la red". El resumen empieza así: "En este escrito presentamos a Google", el protocolo de búsqueda en la red que condujo al imperio empresarial cuyas tecnologías están hoy entrelazadas en el tejido de la vida cotidiana, y cuya influencia económica y social es tan poderosa como la de las grandes empresas de ferrocarriles, acero, automóviles y telecomunicaciones de las revoluciones tecnológicas anteriores. $\mathrm{La}$ tecnología dirigió y la ciencia la siguió.

$\mathrm{Si}$, como dice Visco, "en algún momento se debe salvar realmente una vida", será una tecnología -quizá una vacuna o un medicamentola que haga la tarea. La tecnología vincula la ciencia a la experiencia humana, es lo que hace real la ciencia para nosotros. Un interruptor eléctrico, un avión jet o una vacuna contra el sarampión son mecanismos de causa y efecto que transforman fenómenos que puede describir la ciencia -el flujo de electrones, el movimiento de moléculas de aire, la estimulación de anticuerpos- en resultados confiables: la luz se prende, el avión vuela, el niño se inmuniza. Los fenómenos científicos deben ser reales o las tecnologías no funcionarán. 
La hermosa mentira de Vannevar Bush hace fácil creer que la imaginación científica da nacimiento al progreso tecnológico, cuando en realidad la tecnología fija la agenda de la ciencia, guiándola en sus direcciones más productivas y proporcionando pruebas continuas de su validez, su progreso y su valor. A falta de su validación en el mundo real mediante la tecnología, las verdades científicas serían meras abstracciones. Aquí es donde la mentira ejerce su poder más corruptor: si pensamos que el progreso científico se persigue mejor mediante "el libre juego de intelectos libres", damos a la ciencia un boleto gratuito para definir el progreso sin considerar el mundo que está más allá de ella. Pero si no hay nada con lo cual medir el progreso científico fuera de la misma ciencia, ¿cómo podemos saber cuándo avanza, se detiene o retrocede nuestro conocimiento?

Resulta que no podemos saberlo.

\section{EINSTEIN, TENEMOS UN PROBLEMA}

El mundo de la ciencia ha sido golpeado durante casi una década por las crecientes revelaciones de que grandes conjuntos de conocimiento científico, publicados en artículos revisados por pares, son erróneos. Algunos ejemplos recientes: se reveló que una línea de células de cáncer usada como base para más de mil estudios de investigación del cáncer de mama publicados era en realidad una línea de células de cáncer de piel; una empresa de biotecnología solo pudo replicar seis de cincuenta y tres estudios "trascendentales" publicados que intentó validar; una prueba de más de un centenar de medicamentos potenciales para tratar la esclerosis lateral amiotrófica en ratones no pudo reproducir ninguno de los resultados positivos reportados en estudios anteriores; una compilación de casi ciento cincuenta ensayos clínicos de terapias para bloquear la respuesta inflamatoria humana mostró que si bien las terapias supuestamente fueron validadas usando experimentos con ratones, todas las pruebas fallaron en humanos; una valoración estadística del uso de imágenes por resonancia magnética funcional ( $\mathrm{RM}-\mathrm{f})$ para mapear la función cerebral humana indicó que hasta un $70 \%$ de los resultados positivos reportados en cerca de 40.000 estudios de RM-f publicados podría ser falso, y un artículo que evalúa la calidad total de la investigación biomédica básica y preclínica estimó que entre el 75\% y el 90\% de los estudios no son reproducibles. Entretanto, un minucioso esfuerzo para evaluar la calidad de cien experimentos de psicología revisados por pares solo pudo duplicar el $39 \%$ de los resultados de los documentos originales; se demostró que las mamografías anuales, una vez a la vanguardia en la guerra contra 
el cáncer de mama, poco benefician a las mujeres de cuarenta años; $y$, por supuesto, todos nos hemos sentido aliviados al enterarnos, después de tantos años, de que las grasas saturadas no son realmente tan malas para nosotros. El número de publicaciones científicas retractadas se multiplicó por diez en la primera década de este siglo, y aunque ese número aún se mantiene en el orden de los meros centenares, el creciente número de estudios como los que acabamos de mencionar sugiere que la mala calidad, la ciencia no confiable, inútil o inválida puede ser, de hecho, la norma en algunos campos, y que el número de publicaciones científicamente sospechosas o carentes de valor puede ascender a centenares de miles al año. Si bien la mayoría de las pruebas de mala calidad científica provienen de campos relacionados con la salud, la biomedicina y la psicología, es posible que sea tan mala o peor en muchos otros campos de investigación. Por ejemplo, una revisión de las prácticas estadísticas en economía concluyó que "la credibilidad de la literatura económica es modesta o incluso baja”.

¿Qué se debe hacer con esta creciente letanía de revelaciones y retractaciones desalentadoras? Bueno..., se podría celebrar. "Los casos en que los científicos detectan y corrigen defectos de los trabajos constituyen pruebas de éxito y no de fracaso", escribió en Science, en 2015, un grupo de líderes del establishment científico estadounidense -que incluía presidentes anteriores, presentes y futuros de la Academia Nacional de Ciencias-, "porque demuestran que los mecanismos protectores de la ciencia funcionan”. Pero esta postura feliz ignora las fallas sistémicas en el núcleo de los actuales problemas de la ciencia.

Cuando funciona, la ciencia es un proceso de creación de nuevos conocimientos acerca del mundo, conocimientos que nos ayudan a entender que lo que creíamos saber era incompleto o incluso erróneo. Esta imagen de éxito no significa, sin embargo, que debamos esperar razonablemente que la mayoría de los resultados científicos no sean confiables o que sean inválidos en el momento en que son publicados. Significa, en cambio, que los resultados de la investigación -por imperfectos que sean- son confiables en el contexto del estado existente del conocimiento, y son entonces un paso hacia una mejor comprensión de nuestro mundo y una base sólida para investigaciones posteriores. En muchos campos de investigación, esas expectativas no parecen justificadas, y la ciencia parece estar retrocediendo. Richard Horton, redactor en jefe de Lancet, lo dice así:

E1 juicio a la ciencia es claro: gran parte de la literatura científica, quizá la mitad, simplemente puede ser falsa. Afligida por estudios con tamaños de 
muestra pequeños, efectos diminutos, análisis exploratorios inválidos y conflictos de interés flagrantes, junto con la obsesión por seguir tendencias de moda de dudosa importancia, la ciencia ha dado un giro hacia la oscuridad.

C. Glenn Begley y John Ioannidis -investigadores valientes y visionarios que expusieron la debilidad sistémica de la ciencia biomédicaconcluyeron en un artículo de enero de 2015 que "es imposible avalar el enfoque de que debemos seguir invirtiendo en una investigación en la que la mayoría de sus resultados no se pueden sustanciar y no resistirán la prueba del tiempo". En forma similar, un análisis económico publicado en junio de 2015 estimó que 28 mil millones de dólares al año se desperdician en investigación biomédica reproducible. La ciencia no se está corrigiendo a sí misma, se está destruyendo a sí misma.

Parte del problema tiene que ver con las patologías del sistema científico. La ciencia académica, en especial, se ha convertido en una empresa onanística digna de Swift o de Kafka. Se espera que un científico universitario produzca un flujo continuo de hallazgos sorprendentes y con impacto periodístico. Así es como el gran biólogo E. O. Wilson describe la vida de un investigador académico:

Necesitarás cuarenta horas a la semana para efectuar las tareas docentes y administrativas, otras veinte horas para dirigir una investigación respetable y otras veinte horas adicionales para realizar una investigación realmente importante [...] Haz un descubrimiento importante y serás un científico de éxito, en el sentido verdadero y elitista, en una profesión en la que el elitismo se practica sin pudor [...] No descubras nada y serás poco o nada.

Los incentivos profesionales para que los científicos académicos afirmen su estatus de élite son perversos y alocados, y las decisiones de ascenso y titularidad se centran, por encima de todo, en la cantidad de dólares para investigación que se aportan, de artículos que se publican y de cuán citados son en otros artículos.

Para conseguir fondos para investigación se necesita demostrar que los fondos anteriores produjeron resultados "transformativos" y que el trabajo futuro también los producirá. Para que los artículos sean publicados se necesita citar publicaciones relacionadas que apoyen las hipótesis y resultados del autor. Entretanto, los pares que revisan las propuestas de financiación y los artículos de las revistas juegan en el mismo sistema, compiten por los mismos fondos y son motivados por los mismos incentivos. Para realizar la investigación se necesitan estudiantes de doctorado y becarios de posdoctorado que hagan la mayor parte del trabajo rutinario de experimentación y recolección de datos, y esa es la manera de capacitarse y aculturarse para convertirse en la siguiente generación de científicos académicos que se comportan del mismo modo. Las universidades -que compiten con 
desespero por los profesores de prestigio, los mejores estudiantes de posgrado y los fondos de investigación del gobierno- exageran ante los medios informativos los resultados que provienen de sus laboratorios y fomentan una cultura en la que cada científico pretende que está haciendo trabajos que abren nuevos caminos y resolverán algún problema social urgente. (Los científicos son cómplices de la maquinaria publicitaria; según un estudio, la frecuencia de palabras positivas como "innovador", "novedoso", "robusto"y "sin precedentes" en publicaciones de investigación biomédica de 2014 era casi nueve veces mayor que cuarenta años antes.) La industria de publicaciones científicas existe no para difundir información valiosa sino para que un número creciente de investigadores publique más artículos -hoy del orden de dos millones de artículos revisados por pares al año- a fin de que puedan avanzar profesionalmente. En 2010 se publicaban unas 24.000 revistas científicas revisadas por pares en todo el mundo para satisfacer esta demanda.

Estas cifras no habrían sorprendido al físico e historiador de la ciencia Derek de Solla Price, quien hace más de medio siglo observó: "la ciencia es tan grande que muchos de nosotros empezamos a preocuparnos por la gran masa del monstruo que creamos". En su libro Pequeña ciencia, gran ciencia (1963), Price señaló que el número de científicos crecía con tanta rapidez que solo podría llevar a una "catástrofe científica" de inestabilidad y tensión, y que el crecimiento exponencial del empeño científico traería consigo el declive de la originalidad y la calidad científicas, pues el número de grandes científicos era ahogado progresivamente por el rápido aumento del número de científicos que solo son competentes.

Un resultado acumulativo de estas tensiones convergentes (un resultado que Price no previó) es un sesgo omnipresente bien reconocido que infecta cada rincón de la empresa de investigación básica: el sesgo hacia los nuevos resultados. El sesgo es un atributo inevitable del empeño intelectual humano e interviene en la ciencia de muchas maneras: malas prácticas estadísticas, deficiente diseño de experimentos o modelos y simples ilusiones. Si los sesgos son aleatorios se deben compensar a través de numerosos estudios. Pero como muchos observadores de la literatura científica han demostrado, hay poderosas fuentes de sesgo que impulsan en una dirección: llegar a un resultado positivo, mostrar algo nuevo, diferente, llamativo, transformativo, algo que lleve a figurar como parte de la élite.

Sin embargo, considerar únicamente el sesgo sistémico positivo en un sistema de investigación fuera de control es omitir el asunto más 
profundo y mucho más importante. La razón por la que ese sesgo hoy parece capaz de infectar la investigación con tanta facilidad es que gran parte de la ciencia se ha separado de los objetivos y agendas del sistema de innovación militar-industrial que durante mucho tiempo enfocó y disciplinó la investigación. Nada queda para mantener la investigación honesta salvo las normas internas del sistema profesional de revisión por pares. ¿Y cuán bien se cumplen esas normas? Una encuesta a más de 1.500 científicos publicada en Nature en mayo de 2016 muestra que un $80 \%$ o más cree que la práctica científica se está deteriorando debido a factores como el "reporte selectivo" de datos, la presión para publicar, el deficiente análisis estadístico, la insuficiente atención a la replicación y la inadecuada revisión por pares. En suma, estamos descubriendo qué ocurre cuando la investigación objetiva es guiada por la hermosa mentira de Vannevar Bush: la "catástrofe científica".

\section{LAS RATAS DE CAMPO ESTUDIAN RATONES}

Susan Fitzpatrick, neurocientífica de formación, se preocupa mucho por la ciencia y por lo que Price llamó "la gran masa del monstruo". "La empresa científica solía ser pequeña, y en cualquier campo de investigación todos se conocían; tenía ese tipo de calidad artesanal", dice ella. "Pero el sistema se profesionalizó gradualmente, obtuvo más y más dinero e hizo promesas cada vez mayores. De modo que las cualidades que hacen confiable y honesta a la investigación científica fueron socavadas por la necesidad de alimentar a la bestia, y el sistema creció demasiado para tener éxito". Ella se preocupa especialmente por lo que significa este cambio para la calidad y el valor de la ciencia que se hace en su campo.

Como presidente de la Fundación James S. McDonnell, que financia investigación sobre la cognición y el cerebro, Fitzpatrick está preocupada por el lugar hacia donde fluyen los dólares de investigación. Así como Visco observó lo que ella llamó el "efecto de la rata de campo"-investigadores que saltan de un tema candente al siguiente-, Fitzpatrick también considera que la ciencia es impulsada por una lógica circular interna. "Lo que el investigador desea realmente es algo confiable que ceda a sus métodos", algo que "pueda producir una corriente confiable de datos, porque se necesita tener la siguiente publicación, la siguiente propuesta para obtener fondos".

Por ejemplo, los científicos suelen usar cerebros de ratón para estudiar enfermedades neurodegenerativas como el Parkinson o el Alzheimer, o para estudiar problemas de comportamiento como la adicción o los desórdenes de déficit de atención. Lo bueno de los 
ratones es que ceden a los métodos de los científicos. Se pueden criar en cantidades casi ilimitadas, con rasgos de diseño particulares, como una mutación genética que provoca síntomas similares a los del Alzheimer. Esto hace posible que los investigadores prueben hipótesis específicas, por ejemplo sobre la genética o la neuroquímica de una enfermedad del cerebro de ratón.

Se han desarrollado más de cien diferentes cepas de ratón para estudiar el Alzheimer, y se ha demostrado que numerosos compuestos químicos retardan el curso de síntomas similares a los del Alzheimer en ratones. Pero a pesar de la proliferación de modelos de ratón y de otros animales, solo uno de los 244 compuestos que llegaron a la fase de pruebas en la década de 2002 a 2012 fue aprobado por la FDA como tratamiento para humanos; una tasa de reprobación del 99,6\%, y la única droga aprobada para uso en humanos durante ese periodo no funciona muy bien. ¿YY por qué debería ser diferente? El último ancestro común de humanos y ratones vivió hace 80 millones de años. "Se usan animales que no desarrollan enfermedad neurodegenerativa por sí mismos", explica Fitzpatrick. "Incluso los ratones envejecidos no desarrollan la enfermedad de Alzheimer”. De modo que los investigadores fuerzan el desarrollo de alguna característica-como las placas beta-amiloideas en el cerebro de ratón, o el deterioro cognitivo asociado a la edad-, pero eso no es lo mismo que la enfermedad humana en cuestión, "porque el proceso por medio del cual se crea ese modelo no es la patogénesis de la enfermedad. Su tratamiento se centra en cómo se creó el modelo, no en cómo ocurre naturalmente la enfermedad". Hay pocas razones para creer que lo que se aprende de estos modelos animales nos pondrá en el buen camino para entender trastornos cerebrales humanos, y mucho menos para curarlos.

No es probable que tales preocupaciones pongan freno a la investigación. Una búsqueda de títulos o resúmenes de artículos que contienen las palabras "cerebro" y "ratón" (o "ratones" o "murinos") en la base de datos PubMed del ins arroja más de 50 mil resultados para la década de 2005 a 2015. Si se añade la palabra "rata", la cifra sube a unos 80 mil. Este es un caso clásico de buscar las llaves debajo del farol porque allí está la luz: la ciencia se hace solo porque puede ser. Los resultados se publican y se citan y eso crea, dice Fitzpatrick, "la sensación de que estamos adquiriendo conocimiento cuando no lo estamos adquiriendo". Pero es aún peor. Los científicos citan artículos de los demás porque todo resultado se debe justificar e interpretar en términos de otras investigaciones en áreas relacionadas, uno de esos “mecanismos protectores de la ciencia”. ¿Qué sucede si gran parte de 
la ciencia que se cita es, en sí misma, de mala calidad? Consideremos, por ejemplo, un informe de Science de 2012 que muestra que un medicamento para el Alzheimer llamado bexarotene reduciría la placa beta-amiloidea en cerebros de ratón. Los esfuerzos para reproducir ese resultado han fracasado desde entonces, como reportó Science en febrero de 2016. Pero entre tanto, el artículo ha sido citado en otros 500 artículos, muchos de los cuales pueden haber sido citados numerosas veces. De este modo, la investigación de mala calidad hace metástasis a través de la literatura científica, y se hace imposible distinguir el conocimiento confiable del conocimiento no confiable o falso o carente de sentido.

Un modelo científico permite estudiar una versión simplificada, o características aisladas, de un fenómeno complejo. Esta simplificación es a veces justificada, por ejemplo, si las relaciones de causa y efecto que se estudian en el modelo (como la respuesta de un perfil aerodinámico a la turbulencia en un túnel aerodinámico) operan del mismo modo en el contexto más complejo (un avión que vuela a través de una tormenta). En tales casos se puede tener cierta confianza en que lo que se aprende del modelo se puede aplicar al problema real entre manos. Fitzpatrick piensa que ese razonamiento no se justifica cuando se usan cerebros de ratón para modelar la enfermedad neurodegenerativa humana.

Pero sus preocupaciones por esta forma de abordar la ciencia del cerebro tienen implicaciones más devastadoras cuando los modelos se extienden aún más para explorar los aspectos neurológicos de disfunciones del comportamiento humano:

Como estas cuestiones son sumamente complejas e intentamos reducirlas a
modelos biológicos, se tienen que idear proxies. Un neurocientífico no puede
estudiar directamente lo que hace que alguien cometa un crimen, en vez de
ello dice: "Oh, sé qué es eso, estas personas carecen de control inhibitorio".
Así, ahora eso es algo comprensible, y necesito una tarea que pueda asignar
confiablemente al laboratorio como marcador del control inhibitorio. "Oh,
ya tenemos una tarea, la del tiempo de reacción". Ahora estamos estudiando
algo, llamándolo de otro modo e ideando una hipótesis causal sobre el com-
portamiento de personas formada por vínculos endebles.

El problema, como explica Fitzpatrick, es que en este espacio entre la proxy - p. ej., la medición del control inhibitorio en un ratón, o a ese respecto en una persona-y el comportamiento complejo, como la adicción a las drogas, se encuentra una teoría de lo que causa el crimen y la adicción y el comportamiento sociopático. La teoría “tiene fundamentos ideológicos. Determina el tipo de preguntas que se hacen, la manera de estructurar la investigación, los resultados que se perfilan, la persona a la que se pide que dé el gran discurso". 
Fitzpatrick observa qué ocurre cuando la interacción entre ciencia y tecnología es sustituida por el "libre juego de intelectos libres". Los científicos nunca pueden escapar a la influencia del sesgo humano. Pero el sesgo humano no tiene mucho campo para conseguir un punto de apoyo cuando la investigación está ligada estrechamente al desempeño de una tecnología particular -p. ej., a través del deseo de motores de automóvil más ligeros y más potentes, o de motores de búsqueda en la red más eficientes.

La tecnología mantiene la ciencia honesta. Pero en temas increíblemente complejos, como la enfermedad de Alzheimer y el comportamiento criminal, la conexión entre conocimiento científico y tecnología es endeble, y mediada por muchos supuestos -sobre cómo funciona la ciencia (los cerebros de ratón son buenos modelos del cerebro humano), cómo funciona la sociedad (el comportamiento criminal es causado por la química del cerebro) o cómo funciona la tecnología (las drogas que modifican la química del cerebro son un buen medio para modificar el comportamiento criminal). Los supuestos se convierten en partes invisibles de la forma en que los científicos diseñan los experimentos, interpretan los datos y aplican sus resultados. El resultado son teorías cada vez más elaboradas; teorías que siguen siendo autorreferenciales, y distintas de la tarea de encontrar soluciones a problemas humanos.

Todo esto puede explicar de alguna manera por qué es tan alta la tasa de fracasos de las intervenciones farmacéuticas del Alzheimer. Cuando se usan modelos de ratón para explorar teorías de la salud y del comportamiento del cerebro humano no existe una manera confiable de evaluar la validez de la ciencia ni de los supuestos subyacentes. Esto no significa que los científicos deban empezar haciendo en humanos los experimentos que hoy hacen en ratones. Pero como subraya Fitzpatrick, la enorme cantidad de investigaciones cerebroratón que hoy se hacen es un reflejo de la disfunción interna del sistema de investigación y no del potencial para que "el libre juego de intelectos libres" ayude a aliviar el sufrimiento humano causado por la enfermedad y la disfunción neurológica.

\section{¿PERO ESO ES CIENCIA?}

Los problemas de valores, supuestos e ideología no se limitan a la neurociencia sino que están presentes en toda la empresa científica. Así como Derek Price reconoció la amenaza a la ciencia por su crecimiento insostenible décadas antes de que los síntomas se volvieran penosamente evidentes, el físico Alvin Weinberg también advirtió 
hace mucho tiempo la amenaza de la ideología a la ciencia. Miembro bona fide del complejo militar-industrial, Weinberg dirigió el Laboratorio Nacional Oak Ridge -originalmente parte del Proyecto Manhattan- y fue incansable defensor de la energía nuclear. Como participante en los primeros debates políticos sobre la energía nuclear, mostró su preocupación por los límites de lo que la ciencia podía decirnos sobre asuntos sociales y políticos complejos.

En su artículo de 1972 “Ciencia y transciencia”, Weinberg observó que la sociedad invocaba cada vez más a la ciencia para entender y abordar los complejos problemas de la modernidad, muchos de los cuales se remontaban, por supuesto, a la ciencia y la tecnología. Pero él acompañó este reconocimiento con una idea más profunda y sugerente: dichos problemas "están ligados a las respuestas a preguntas que se pueden hacer a la ciencia aunque la ciencia no las puede responder". Y llamó "transciencia” al estudio de tales preguntas. Si la ciencia tradicional aspira a un conocimiento preciso y confiable de los fenómenos naturales, la transciencia persigue realidades contingentes o en flujo continuo. Los objetos y fenómenos que estudia la transciencia-poblaciones, economías, sistemas diseñados-dependen de muchas cosas diferentes, incluidas las condiciones en las que son estudiados en un momento y un lugar dados, y de la decisión de los investigadores sobre cómo definirlos y estudiarlos. Esto significa que los objetos y fenómenos que estudia la transciencia nunca son absolutos sino que son variables, imprecisos e inciertos y, por tanto, siempre sujetos a interpretación y debate.

En cambio, argumenta Weinberg, ciencias naturales como la física y la química estudian objetos que pueden ser caracterizados por un pequeño número de variables medibles. Por ejemplo, en física clásica, una vez se conocen la posición, la velocidad y las fuerzas que actúan sobre un objeto físico, se puede predecir el movimiento de ese objeto, bien sea un guijarro o un planeta. (Ese no es el caso en física cuántica, en la cual la posición y la velocidad de partículas individuales no se pueden medir con precisión simultáneamente. Pero, señala Weinberg, "incluso en física cuántica, podemos hacer predicciones precisas" sobre distribuciones estadísticas de moléculas o átomos o partículas.) Además, los objetos de estudio -bien sea la masa de un electrón, la estructura de una molécula o la energía liberada por una reacción química- se pueden definir con precisión y caracterizar de manera inequívoca, de modo que todos los científicos pueden estar de acuerdo. Como él dice: "Cualquier átomo de hidrógeno es igual a cualquier otro átomo de hidrógeno”. 
Esta combinación de comportamiento predecible y atributos fundamentales invariantes es lo que hace tan valiosas a las ciencias físicas en el avance tecnológico; cuando se confinan al ambiente controlado del laboratorio o al diseño planeado de una tecnología, el electrón, el fotón, la reacción química o la estructura cristalina se comportan como se supone que se comportan casi todo el tiempo.

Pero muchas otras ramas de la ciencia estudian cosas que no se pueden caracterizar inequívocamente y que se pueden comportar de un modo no predecible incluso en condiciones controladas, como una célula o un cerebro, o un área particular del cerebro, o un tumor o una condición psicológica. $\mathrm{O}$ una especie de pájaro. $\mathrm{O}$ un vertedero de desechos tóxicos. O un salón de clase. O "la economía" o el clima de la tierra. Esas cosas pueden diferir de un día a otro, de un lugar a otro o de una persona a otra. Su comportamiento no se puede describir y predecir mediante el tipo de leyes generales que invocan los físicos y los químicos, porque sus características no son invariables sino que dependen del contexto en el que se estudian y de cómo se definen. Por supuesto, los científicos se esfuerzan por encontrar maneras útiles de caracterizar las cosas que estudian, como la noción de especie para clasificar entidades biológicamente distintas, o el PIB para definir la escala de la economía de una nación, o el ci para medir la inteligencia de una persona, o la biodiversidad para evaluar la salud de un ecosistema, o la temperatura atmosférica global promedio para evaluar el cambio climático. O utilizan estadísticas para caracterizar el comportamiento de una clase heterogénea de cosas, por ejemplo, el índice de accidentes de conductores de cierta edad, o la incidencia de un tipo de cáncer en personas con cierta ocupación, o la probabilidad de que cierto tipo de tumor haga metástasis en un ratón o una persona. Pero esas maneras de nombrar y describir objetos y fenómenos siempre tienen un costo; el costo de ser a lo sumo solo una aproximación de la realidad compleja. Así, los científicos pueden criar una cepa de ratón que tiende a mostrar la pérdida de la función cognitiva con el envejecimiento, y las semejanzas entre diferentes ratones de esa cepa pueden aproximar el tipo de homogeneidad que poseen los objetos estudiados por la física y la química. Esto hace que el ratón sea un objeto útil de investigación. Pero debemos asumir el costo de esa utilidad: la conexión entre los fenómenos estudiados en esa cepa de ratón y los fenómenos más complejos de enfermedades humanas como la enfermedad de Alzheimer es endeble o incluso, como señala Susan Fitzpatrick, inexistente. 
Para Weinberg, quien abogaba por la energía nuclear civil, calcular la probabilidad de un accidente catastrófico de un reactor nuclear era un excelente ejemplo de un problema transcientífico. "Puesto que la probabilidad es tan pequeña, no hay posibilidad práctica de determinar directamente esta tasa de fracaso, es decir, construyendo, por ejemplo, 1.000 reactores, usándolos 10.000 años y tabulando la historia de su funcionamiento". En vez de ciencia, nos quedamos con una mezcla de ciencia, ingeniería, valores, supuestos e ideología Así, como explica Weinberg, el debate transcientífico "inevitablemente teje hacia atrás y hacia adelante a través de la frontera entre lo que es y lo que no es conocido y conocible”. Más de cuarenta años después $-y$ de tres grandes accidentes-, científicos y defensores, armados con datos y resultados de investigación, siguen debatiendo los riesgos y las promesas de la energía nuclear.

Para asegurar que la ciencia no fuese totalmente infectada por sesgos y opiniones personales, Weinberg reconoció que era esencial que los científicos "establezcan cuáles son los límites del hecho científico, dónde termina la ciencia y dónde empieza la transciencia”. Pero eso exigiría "el tipo de honestidad desinteresada que es difícil ejercer para un científico o un ingeniero que debe mantener un cargo o un estatus”. Además, eso “no es nada fácil, porque los expertos a menudo no concuerdan en la medida y la confiabilidad de su pericia".

Los llamamientos de Weinberg a "la honradez desinteresada" al trazar las líneas de pericia han sido muy desatendidos, pues durante los últimos cuarenta años los científicos no han procurado distinguir entre transciencia y ciencia sino intentado -mediante lo que equivale a una especie de alquimia moderna- transmutar la transciencia en ciencia. De hecho, lo maravilloso de la transciencia es que se puede seguir investigando; que se puede, como dice Fitzpatrick, crear "la sensación de que estamos adquiriendo conocimiento cuando no lo estamos adquiriendo", sin acercarse a una respuesta final o útil.

En ausencia de una aplicación tecnológica que pueda seleccionar verdades útiles que funcionen en el mundo real de interruptores eléctricos, vacunas y aviones, no hay una manera "correcta" de discriminar u organizar la masa de verdades que crean los científicos. Por ello, para tomar otro ejemplo incesantemente debatido, después de décadas de intensa investigación de los efectos de la reducción de la sal sobre la salud, hoy hay mucha menos claridad que en 1972, cuando un artículo reportó: "Las pruebas de que la sal induce hipertensión permanente y fatal es directa, cuantitativa e inequívoca en ratones". Cuatro década después, el director de los Centros de Control y Prevención 
de Enfermedades afirmó que cien mil muertes al año en Estados Unidos se pueden atribuir al exceso de sodio en la dieta, aunque un importante meta-análisis de 167 pruebas aleatorias controladas y 13 estudios de población desde 1950 no encontró una conexión clara entre reducción de la sal y resultados de salud. Los científicos y los grupos de interés se alinean en ambos lados del debate e impugnan con avidez las motivaciones y la investigación de aquellos con los que están en desacuerdo.

La profusión de verdades parciales, cada una defendida por su propio grupo de expertos, es lo que sucede cuando la ciencia intenta responder preguntas transcientíficas como: ¿para alimentar a la creciente población mundial se necesitan cultivos genéticamente diseñados? ¿La exposición al Bisfenol A (o a cualquiera de otros diez mil productos sintéticos) afecta adversamente el desarrollo de la niñez o perjudica de otra manera la salud? ¿Los mercados abiertos benefician a todos los socios comerciales? ¿Cuáles serán los costos económicos futuros del calentamiento climático para una nación o región particular? ¿Las pruebas estandarizadas mejoran los resultados de la enseñanza? ¿Por qué aumenta la obesidad en Estados Unidos, y qué se puede hacerse al respecto?

Si los debates de investigación científica y los debates políticos sobre tales preguntas parecen alargarse sin fin, no hay duda de que una razón es que tenemos expectativas erróneas sobre la ciencia. La creencia común es que la verdad científica es unitaria: hay un hecho de la materia, y por ello la luz siempre se enciende cuando muevo el interruptor. Pero las preguntas transcientíficas a menudo revelan verdades múltiples, dependiendo en parte de qué aspectos de un asunto deciden investigar los científicos y cómo realizar tal investigación. No tiene sentido preguntar quién tiene razón en esos casos; lo mejor que podemos esperar es entender por qué los expertos están en desacuerdo, lo que suele depender de decisiones técnicas sobre cómo hacer la investigación y analizar los datos, para no mencionar los sesgos ocultos que ayudan a determinar esas decisiones. Consideremos la pregunta “¿los cultivos modificados genéticamente son más productivos que los cultivos tradicionales?”. Algunos investigadores prefieren responderla examinando pruebas de campo donde se controlan cuidadosamente variables como el clima y el tipo de suelo. Otros prefieren hacer encuestas en fincas reales porque reflejan la variabilidad del mundo real. Estos dos enfoques a menudo producen resultados contradictorios, y con base en los datos no hay manera de juzgar cuál proporciona una mejor guía para el futuro. 
A veces el problema no es que sea difícil evaluar los hechos sino que es demasiado fácil. Por ello la ciencia casi nunca proporciona una solución a asuntos de controversia política. En general hace lo contrario, ofrece verdades revisadas por pares y, así, validadas culturalmente, que se pueden seleccionar y ensamblar del modo que sea necesario para apoyar la posición y la solución de política preferida. Si esta observación parece inverosímil o exagerada cabe preguntar por qué después de cuarenta años de investigar los riesgos y beneficios de las mamografías su efectividad es más debatida que nunca. De manera similar, después de más de veinticinco años y de 15 mil millones de dólares en investigación para evaluar la seguridad del depósito de residuos nucleares situado en Yucca Mountain, Nevada, nada ha resultado más allá del atasco político. En ningún caso la ciencia se adhiere a una verdad unitaria. Lo que tenemos, en cambio, es transciencia que "teje hacia atrás y hacia adelante a través de la frontera entre lo que es y lo que no es conocido y conocible".

Hay una muy buena razón por la que el problema de la mala calidad de la ciencia se percibe de manera más visible en la investigación biomédica. Aunque la financiación del gobierno para ciencia biomédica en Estados Unidos es igual a la de los demás campos de investigación en conjunto, las enfermedades siguen sin cura, la innovación farmacéutica se ha desacelerado y la inversión empresarial es muy riesgosa debido a las asombrosas tasas de fracaso en las pruebas de nuevos medicamentos. La ciencia biomédica está fracasando en la prueba de la verdad de la tecnología. Pero la amenaza más difícil y peligrosa para la ciencia proviene de campos de investigación donde las apuestas son altas pero la validez de la ciencia no se puede determinar porque no está ligada estrechamente al avance tecnológico hacia un objetivo específico compartido (como curar el cáncer de mama). En estos casos se presentan verdades parciales, cualquier de las cuales puede impulsar la carrera de un investigador y atraer a un grupo de creyentes entre científicos, grupos de interés políticos y miembros del público por igual.

Incluso el alardeado consenso científico sobre el cambio climático -que en gran medida se basa en física fundamental bien entendida ya hace más de un siglo- solo se aplica a una afirmación estrecha sobre el impacto humano perceptible en el calentamiento global. Cuando se hacen preguntas sobre la tasa y la gravedad de impactos futuros, o sobre los costos y los mejores caminos para abordarlos, no hay nada semejante al consenso entre expertos. Los modelos matemáticos de las tasas futuras y las consecuencias del cambio climático 
son muy sensibles a supuestos sobre cosas totalmente impredecibles (como las tendencias de crecimiento económico o de la innovación tecnológica), y por ello los modelos regurgitan series interminables de hechos transcientíficos que permiten hacer afirmaciones y contra afirmaciones, en apariencia todas respaldadas por la ciencia, acerca de cuán urgente es el problema y qué se debe hacer. Si, en cambio, procuráramos ejercer la "honradez desinteresada" por la que abogaba Weinberg y reconocer los supuestos que nos llevaron a los resultados de los modelos del clima (o del ratón), tendríamos que abandonar cualquier pretensión de una verdad científica absoluta que da a esos resultados su legitimidad en la sociedad.

\section{DATAGEDÓN ${ }^{1}$}

Estas dificultades están a punto de empeorar. Muchos campos de la ciencia hoy apuestan su futuro a lo que a veces se llama "datos masivos" (big data): la creación de enormes y nuevos conjuntos de datos mediante nuevos instrumentos tecnológicos que hacen posible recolectar, almacenar y analizar cantidades casi infinitas de información. Así, por ejemplo, se nos dice que la Iniciativa del Cerebro del presidente Obama "abrirá nuevas puertas para explorar cómo el cerebro registra, procesa, usa, almacena y recupera vastas cantidades de información, y arrojar luz sobre los complejos vínculos entre función cerebral y comportamiento". Que la iniciativa de la Medicina de Precisión "promoverá estrategias de tratamiento y prevención adecuadas a las características únicas de las personas, incluidas la secuencia de su genoma, la composición de microbiomas, la historia clínica, el estilo de vida y la dieta". Que el proyecto internacional Future Earth intentará "observar, monitorear, explicar y modelar el estado del planeta y de sus sociedades", para que quienes toman las decisiones puedan "acercarse a la predicción y administración informada del sistema Tierra”. Que la Red del Observatorio Ecológico Nacional intentará lo mismo en los ecosistemas, con "infraestructura y ciberinfraestructura de medición que proporcionen datos estandarizados y calibrados a la comunidad científica a través de un portal de datos único de libre acceso". Que la Iniciativa de Observatorios del Océano "medirá las variables físicas, químicas, geológicas y biológicas del océano y del fondo marino [...] para mejorar la detección y la predicción de cambios ambientales y de sus efectos sobre la biodiversidad, los ecosistemas costeros y el clima”.

\footnotetext{
1 Alusión al término "Armagedón” que designa la catástrofe del fin del mundo. En la Biblia es el lugar donde se librará la batalla final (Apocalipsis 16, 16) [N. del T.].
} 
El imperativo del avance tecnológico enfoca la investigación científica y proporciona una prueba de la validez del nuevo conocimiento científico. Los datos masivos hacen lo contrario, convierten la ciencia en un océano de datos sin restringir hacia dónde puedan llevar. La dificultad de esta manera de hacer ciencia es que, para cualquier gran conjunto de datos sobre un problema complejo con muchas variables, el número de vínculos causales posibles entre las variables es incalculablemente mayor que el número que un científico puede analizar y probar. Por ejemplo, los investigadores han identificado más de un centenar de variables que pueden influir en la obesidad, de los genes a la educación, del estrés laboral a la rapidez con que se come y aun si se fue amamantado. Explorar las relaciones entre un pequeño número de variables combinadas generaría miles de millones de hipótesis posibles para probar. La probabilidad de que se encuentre una que revele relaciones causales importantes es entonces sumamente pequeña, mientras que abundan las oportunidades para introducir sesgos o descubrir correlaciones carentes de sentido. De modo que aun si se obtiene un resultado positivo, es probable que sea espurio. Como explica John Ioannidis en su famoso artículo de 2005, "Por qué la mayoría de los resultados de investigación publicados son falsos", el problema de buscar un pequeño número de relaciones verdaderas posibles en grandes conjuntos de datos

invierte totalmente nuestra manera de ver los resultados científicos. Tradicionalmente, los investigadores ven con emoción efectos grandes y muy significativos como signos de descubrimientos importantes. Es más probable que efectos demasiados grandes y altamente significativos sean en realidad señales de grandes sesgos en la mayoría de los campos de la investigación moderna.

Pero no importa; una vez se tiene un resultado positivo, Internet pone a disposición la literatura científica mundial, y sin esfuerzo alguno se pueden pescar artículos revisados por pares para dar credibilidad al descubrimiento. $\mathrm{E}$ incluso si se llega a confirmar un vínculo causal verdadero, para que sea útil probablemente habría que conectarlo a otros vínculos, cada uno de los cuales en sí mismo quizá no sea verdadero. Tal vez las personas obesas con menos educación, más estrés laboral y un marcador genético específico coman más rápidamente que otras, pero la razón por la que son obesas puede ser muy distinta, como no tener tiempo para hacer ejercicio porque viven lejos del trabajo.

Si los modelos de ratón son como buscar las llaves bajo el farol, los datos masivos son como buscarlas en todo el planeta solo porque se puede, aunque no se sepa qué forma tienen o dónde se cayeron o si abren la puerta. 
Por tanto, otra razón para que la ciencia biomédica esté a la vanguardia de otros campos en términos de revelaciones de irrepetibilidad y resultados falsos puede ser que apostó su futuro a los datos masivos antes que otros campos de la ciencia; en especial mediante el mapeo del genoma humano, sobre el cual casi todos están de acuerdo en que fue un poderoso catalizador de la investigación científica al generar ingentes cantidades de datos pero que, a lo sumo, produce beneficios modestos en atención de la salud. Como señaló en un artículo reciente Michelle Gittelman, profesora de administración en la Universidad de Rutgers que estudia la innovación farmacéutica:

La revolución de la biotecnología estaba condenada al fracaso, dados los límites de la ciencia predictiva para resolver problemas en fenómenos naturales complejos [...] La experiencia de la genética en investigación médica ha demostrado que una frontera móvil en el conocimiento científico no se traduce en un avance correspondiente en la innovación tecnológica.

Ella sugiere, de hecho, que "la aplicación de la genética y de la ciencia molecular al descubrimiento médico podría obstaculizar el progreso, en vez de acelerarlo". La situación con respeto al cáncer se resume en un ensayo, publicado en Cell en 2014, de Robert Weinberg del Miт, conocido investigador del cáncer:

Los datos que hoy generamos superan abrumadoramente nuestra capacidad de interpretación, y los intentos de la nueva disciplina de "biología de sistemas" para enfrentar esta deficiencia hasta ahora han producido pocos conocimientos sobre biología del cáncer más allá de los que revela la simple intuición casera.

Cegada por la mentira, cautivada por el poder de las nuevas tecnologías no para resolver problemas discretos sino para reunir, almacenar, probar y analizar miles de millones de terabytes de datos sobre todo lo que sucede en todas partes - desde el núcleo de la Tierra hasta el cerebro humano y el espacio exterior- y dedicada religiosamente a la noción de que más información, más publicaciones revisadas por pares y más financiación son siempre un paso en la dirección correcta, cualquiera que sea, la comunidad científica y sus partidarios hoy se afanan por crear la infraestructura y las expectativas que pueden llevar a que la esencia del legado de la ciencia sea la falta de confiabilidad, el caos del conocimiento y la multiplicidad de verdades contradictorias.

La ciencia hoy se ve atenazada entre las revelaciones de que áreas enteras de investigación científica no son buenas, y la producción alocada de conocimiento no verificable relevante para las preguntas sin respuesta de la transciencia. Aunque el caos resultante compromete el progreso tecnológico -dirigido, p. ej., a prevenir o curar el cáncer de mama-, la frontera entre verdad objetiva y creencias subjetivas parece estar disolviéndose en forma gradual y aterradora. 


\section{LA ADMINISTRACIÓN DE LA VERDAD}

Durante veinte años Jeff Marqusee tuvo que encontrar soluciones prácticas para problemas ambientales en el DD. Su enfoque era una herejía. "Se necesita administrar la investigación". Con un doctorado del mit, Marqusee también es un hijo de la mentira. "Culturalmente fui formado como científico básico. Estudié física estadística. Mi tesis era tan esotérica e inútil como podía ser. Era divertida”. Dobla una rodilla a modo de disculpa, como todos deberíamos, y luego prosigue: "No se necesita administrar al chico solitario que es inteligente. Ese no es el problema". La mayoría de los científicos no son Einstein ni E. O.Wilson, y la mayor parte de la investigación no tiene en sí misma el potencial para ser trascendental. Si la gente espera que la investigación científica -incluso la investigación básica de largo plazo- contribuya a un objetivo más amplio, tiene que haber algún mecanismo de rendición de cuentas para orientarla hacia ese objetivo. Igual que Visco y Fitzpatrick, Marqusee piensa que la carencia de ese mecanismo ha llevado a "un sistema que produce demasiadas publicaciones" y tiene que "alimentar muchas bocas".

Cuando Marqusee habla de la necesidad de "administrar la investigación" eso no significa decir a los científicos cómo deben hacer su trabajo ni en qué trabajar; sino asegurar que la ciencia que se hace tenga sentido en términos del objetivo al que supuestamente contribuye. El tipo de preguntas que Marqusee debía responder en el DD era esencialmente transcientífico: las verdades necesarias y las soluciones efectivas eran contextuales y variaban de una situación a la siguiente. Estaban sesgadas hacia lo local y lo específico, y no hacia descubrimientos que mejoraran la carrera profesional. Para averiguar, por ejemplo, "cómo proteger a mis soldados" de venenos como el plomo, el cadmio y el cromo en el suelo de las bases militares, primero había que entender cómo incide el suelo seco y de mala calidad típico de las bases militares en la exposición de los soldados a químicos tóxicos Y, a la vez, cómo afecta la dieta de los soldados la química estomacal y la toxicidad de los diversos productos químicos una vez entran en el cuerpo.

Los programas de Marqusee produjeron métodos de descontaminación del agua subterránea menos costosos que los que desarrollaron otras entidades del gobierno o los que utilizaba el sector privado. Su oficina financió investigaciones que hicieron posible que la Agencia de Protección Ambiental fijara estándares de exposición al plomo más estrictos en las bases militares. Él apoyó investigación ecológica sobre la mejor manera de proteger al pájaro carpintero cabecirrojo que anida 
en los bosques de las bases militares del sureste de Estados Unidos, que estaba en peligro de extinción; y durante el proceso mejoró el ecosistema a la vez que el entrenamiento militar.

Si se trata el paisaje para mantener un buen hábitat para pájaros carpinteros cabecirrojos también se crea un bosque mucho más bello, más resistente y mejor para el entrenamiento militar. Y solo se debe tener la precaución, durante algunas semanas, cuando llega la época de anidación, de que no se disparen armas de fuego cerca de ellos.

El conocimiento científico necesario para resolver este tipo de problemas nunca sería generado espontáneamente por "el libre juego de intelectos libres". Marqusee entendió que si financiaba científicos y dejaba que hicieran el trabajo por sí solos, él terminaría con mucho conocimiento inútil y muchos problemas sin resolver. No es que no financiara investigación fundamental rigurosa: "Claro que queríamos tener publicaciones de alta calidad, queríamos avanzar en el campo científico, pero ¿por qué? Porque teníamos un problema que queríamos resolver". La hermosa mentira insiste en que los científicos solo deben ser responsables ante ellos mismos. El consejo de Marqusee a su personal era exactamente lo contrario: "No tengan electores en la comunidad de investigación, ténganlos únicamente en la comunidad de usuarios finales".

A veces debía poner fin a proyectos científicamente productivos que no contribuían a su misión. Uno de ellos - “un proyecto de investigación básico, una gran propuesta”- prometía elaborar indicadores que mostraran los efectos desfavorables de las actividades de una instalación militar sobre una especie animal protegida antes de que sufriera un grave descenso demográfico. Pero durante una revisión del proyecto Marqusee entendió que el investigador identificaría y mediría "todo tipo de biomarcadores del nivel de estrés esteroidal, decenas de ellos", y que al final encontraría muchísimas correlaciones, así como se pueden encontrar millones de razones por las cuales los estadounidenses se están volviendo obesos, o por las cuales no está mejorando el desempeño de la escuela pública, o por las cuales la falta de control inhibitorio lleva e convertirse en criminales drogadictos. Tales resultados habrían estimulado el debate y la investigación, llevando a publicar más artículos y al avance profesional; pero no habrían ayudado a que el administrador de una base militar predijera las causas específicas de la reducción de una especie particular.

"De modo que liquidamos el proyecto". Y, sin embargo...

El científico buscaba algunos biomarcadores muy innovadores. Y podría haber habido un subproducto imprevisto que podría haber sido útil, lo que es 
siempre la justificación de toda investigación básica, ¿cierto? La Fundación Nacional para la Ciencia nunca habría liquidado el proyecto.

Cierto. No solo la Fundación Nacional para la Ciencia nunca lo habría liquidado, sino que ejemplifica el espíritu del área de datos masivos que se está convirtiendo en la nueva faceta de la ciencia.

Pero si el cuerpo de electores, para usar el término de Marqusee, es la sociedad, no los científicos, la elección de los datos y del conocimiento que se necesitan debe estar informada por el contexto del mundo real del problema que se debe resolver. Es probable que las preguntas que se hagan sean muy diferentes si el objetivo es resolver un problema concreto y no solo mejorar la comprensión. Por ello la simbiosis entre ciencia y tecnología es tan poderosa: la tecnología enfoca y disciplina a la ciencia. Pero la hermosa mentira de Vannevar Bush llevó a culturas institucionales organizadas e incentivadas en torno a la búsqueda de más conocimiento y no a la solución de problemas. Marqusee dice con sarcasmo que la mejor manera de reorientar a los científicos sería "pagarles por ocuparse del problema".

O quizá enviarlos al Cuerpo de Paz antes de que vayan a la escuela de posgrado. Al menos eso es lo que hizo J. Kumar, después de su pregrado en física, en Stanford. Trabajando en un pueblo sudafricano durante dos años, Kumar empezó a ver la ciencia como un medio de apalancar su impacto en el mundo, y esto lo volvió escéptico ante la cultura de la mentira. Igual que Marqusee, Kumar entiende y aprecia el papel de la ciencia fundamental, pero también reconoce que la lógica de la mentira justifica "profundizar cada vez más en un solo tema sin detenerse a preguntar por qué lo estamos haciendo”. Él piensa que hay "espacio para más intencionalidad en la manera de hacer ciencia”.

En el programa de doctorado en física aplicada de Harvard, Kumar comenzó con el interés de vincular la ciencia a las necesidades de atención de la salud en países pobres. Rápidamente se enfocó en una pregunta específica: “¿Cómo difundir la información que obtenemos en estudios sobre la sangre en entornos de bajos recursos?". Esa pregunta lo impulsó en dos direcciones: hacia el contexto social, para ver qué necesidades se podían satisfacer con mejor información sobre la sangre; y hacia la ciencia, para ver qué teorías e instrumentos podían proporcionar esa información. Entonces habló con médicos que tenían experiencia de trabajo en África, y con científicos en su laboratorio y en otras partes, lo que eventualmente llevó a una convergencia: una técnica para separar proteínas usando una centrífuga de cincuenta años de antigüedad. Esa técnica se podía usar para separar células sanguíneas, lo que podía ayudar a diagnosticar la anemia de células 
falciformes, un problema de salud que carecía de un procedimiento de diagnóstico rápido, barato, portátil y confiable. Kumar termina la historia con modesta prontitud: "Así pudimos conseguir algunos colaboradores, empezar a investigar, hacer los primeros experimentos y obtener resultados positivos iniciales", demostrando que la célula falciforme se podía diagnosticar confiablemente mediante separación densimétrica. "Esto nos permitió avanzar realmente e iniciar la búsqueda de financiación y validación clínica, y hacer ensayos, lo que consumió el resto de mi doctorado". La prueba que ideó se puede hacer in situ, en quince minutos, y cuesta menos de un dólar. Kumar era un complejo médico-industrial de una sola persona, que coordinó todos los aspectos del proceso de investigación, incluido el desarrollo comercial, recurriendo al desempeño tecnológico como árbitro despiadado del progreso científico. En suma, hizo que su investigación rindiera cuentas ante el usuario final y no ante sus pares científicos.

Esto es, en suma, lo que pide Fran Visco. Por supuesto, poner fin al cáncer de mama es un problema científico y organizativo mucho más complejo que encontrar una manera barata y rápida de diagnosticar la anemia de células falciformes. Pero esa parece ser una razón más para que, después de gastar miles de millones de dólares $-\mathrm{y}$ de cuarenta mil mujeres que aún mueren al año por esa enfermedad tan solo en Estados Unidos-, alguien se haga responsable de dirigir el sistema hacia una solución.

Por ello, Visco y sus colegas decidieron que la NBCC asumiera esa carga y empezara a administrar la ciencia. "Nos cansamos después de tantos años de ver que mucho de lo mismo no iba a hacer una gran diferencia. No nos interesa seguir financiando ese tipo de cosas". Trabajando primero con la comunidad de pacientes-defensores, la NBCC identificó una pregunta clave que podría enfocar la investigación: ¿cómo desarrollar una vacuna preventiva del cáncer de mama? En marzo de 2010, la NBCC reunió un grupo diferente de científicos para ver si esta era una pregunta que se podía responder de manera concluyente dado el estado actual del conocimiento. La opinión de consenso del grupo fue que se podía y se debía intentar.

Sin fondos cuantiosos para financiar directamente la investigación, la NBCC empezó a reunir científicos para comparar ideas y resultados, fomentar la colaboración en ciernes y acelerar el proceso de desarrollo y comprobación de una vacuna. Estableció una fecha límite -2020para poner fin al cáncer de mama y apostó su credibilidad al logro de al menos un avance importante para esa fecha. La fecha ha sido muy criticada por la comunidad de investigadores predominante -“el 
descubrimiento no tiene fecha límite" fue la réplica previsible en un editorial de Nature. Visco lo entiende perfectamente; así es cómo los científicos evaden la responsabilidad. La fecha límite es la peliaguda y muy riesgosa alternativa de la NBCC. Visco rechaza la idea de que, después de décadas de investigación y miles de millones de dólares en financiación, poner fin al cáncer de mama sea todavía un asunto de esperar a que alguien haga un descubrimiento inesperado. "Decidimos que debíamos tomar el control porque tenemos una agenda; nuestra agenda es poner fin al cáncer de mama y salvar vidas, y eso es todo".

La NBCC ha atraído una treintena de científicos, muchos de ellos líderes de grupos de investigación del cáncer, para trabajar en el proyecto de vacunas Artemisa, hoy en su sexto año. "Estas son personas que nunca habrían colaborado y nunca se habrían hecho esta pregunta de no ser por nosotros", dice Visco. Ellas seleccionaron los antígenos que serán el blanco de la vacuna, y empezaron a planear los ensayos clínicos, a pensar cómo se pueden asegurar la asequibilidad y el acceso si las pruebas tienen éxito, e incluso a explorar la idea de crear una compañía de vacunas sin ánimo de lucro. Con el esfuerzo de la vacuna en marcha, la NBCC también inició una segunda etapa del proyecto Artemisa, enfocada en detener la metástasis del cáncer de mama a otras partes del cuerpo, un problema que, como la investigación de la vacuna, era muy desatendido por la comunidad de investigación predominante.

El proyecto Artemisa difiere de la ciencia usual de muchas maneras. Es pequeño, colaborativo y enfocado no en producir buena ciencia por sí misma, ni en obtener ganancias, sino en resolver un problema. Su agenda de investigación proviene de pacientes-defensores, no de científicos. La responsabilidad con los usuarios finales - pacientes de cáncer de mama pasados, presentes y futuros- está incorporada en el programa. Frank Calzone, quien trabajó veinte años en la compañía de biotecnología Amgen, al final como director ejecutivo científico, y quien lleva tiempo como asesor técnico de la NBCC, considera que el esfuerzo de la vacuna Artemisa combina el enfoque y las fechas límite de la industria con la apertura y la colaboración de la academia. "Es un híbrido industria-academia, en el que los defensores están a cargo, y eso es único". Ante todo, da crédito a los pacientes-defensores por entender e impulsar la ciencia de una manera diferente. "Se preocupan por la prevención primaria del cáncer de mama. Nadie lo consideraba posible en el mundo de las vacunas ni en de la farmacología”. En 2010, cuando Artemisa se estaba organizando, "había inmunólogos tradicionales que decían que estábamos locos”. Seis años después, Calzone 
está "muy impresionado por haber aprendido cosas que nunca había previsto sobre la viabilidad de este enfoque”. Él da crédito a Visco: "Fran, al ocuparse de algo imposible, logró que la gente se interese en replantear el dogma”.

¿La vacuna tendrá éxito? Nadie puede saberlo, pero es la pregunta equivocada. La pregunta correcta es por qué se necesitó un abogado valiente para que la ciencia hiciera lo que la mentira nos dice que ocurrirá automáticamente.

\section{DE VUELTA A NUESTRO MUNDO}

¿La ciencia es hoy el último candidato para entrar en la lista creciente de instituciones fallidas que parece caracterizar a nuestra sociedad? Igual que la política democrática, la justicia criminal, la asistencia de la salud y la educación pública, la organización y la cultura de la ciencia son capturadas por una inercia desalentadora y egoísta, y un conjunto de valores que reflejan un mundo que ya no existe.

Pero la ciencia tiene ventajas sobre otras instituciones escleróticas. En la empresa científica existen innumerables nichos donde se pueden explorar otras formas de organizar la investigación. Sí, el sistema que cada año genera veinticinco mil nuevos científicos prometedores con doctorado y unos dos millones de nuevos artículos de dudoso valor ejemplifica el rígido paradigma dentro del que opera gran parte de la ciencia. Pero entre los científicos jóvenes que conoce, Kumar observa un "anhelo" por hacer algo más que agrandar la pila de conocimientos esotéricos. Su reto es encontrar aquellos nichos del sistema que les permitan aportar algo más, y hacer posible que el sistema se reoriente, gradualmente, en una mejor dirección. De hecho, un atributo esperanzador de la ciencia es que puede ser apalancado incluso por individuos y organizaciones pequeñas, para que tenga grandes efectos, como han demostrado Visco, Marqusee y Kumar.

En el futuro, las instituciones científicas más valiosas estarán ligadas estrechamente a personas y lugares cuyos problemas urgentes se necesita resolver; cultivarán una sólida responsabilidad con aquellos para quienes las soluciones son importantes; incentivarán a los científicos para que se ocupen de los problemas más que de la producción de conocimiento. Vincularán las agendas de investigación a la búsqueda de mejores soluciones -a menudo tecnológicas- más que a la comprensión por sí misma. La ciencia que produzcan será de mayor calidad, porque así debe ser. Entretanto, el paradigma hoy dominante seguirá desmoronándose bajo el peso de sus contradicciones, pero también seguirá captando la mayor parte de los recursos 
e insistiendo en su elevado estatus social y político. E1 renombrado químico George Whitesides (quien, quizá no por casualidad, fue tutor de doctorado de Kumar) argumentó en The Economist, en 2012, que en el siglo anterior, años más años menos, la ciencia impulsada por la mera curiosidad solo produjo uno o dos avances fundamentalmente transformadores (la mecánica cuántica y quizá la genómica) y que, dado este desempeño, mantener la ciencia separada de la tecnología “puede ser un lujo costoso". Una manera diferente de decirlo sería que el tipo de exploración indisciplinada que Vannevar Bush vendía en 1945 hoy se debe considerar a la misma luz que los viajes espaciales, el apoyo a las artes o a los monumentos públicos y la protección de la tierra virgen. Por valedera y ennoblecedora que sea en sí misma, no se puede justificar en términos de solucionar problemas o guiar las decisiones de política o, incluso, de llevar a verdades verificables.

A esta luz, Susan Fitzpatrick enfrenta un reto muy difícil. Ella quiere que la fundación filantrópica que dirige maximice el potencial de la neurociencia para ayudar a reducir el sufrimiento humano, pero no cree que este campo aún tenga mucho que decir sobre la reducción de la terrible carga de la mayoría de las enfermedades cerebrales. Piensa que gran parte de la neurociencia ha sido seducida por lo que llama el "dogma del reduccionismo". "Todos están convencidos de que si se puede encontrar la explicación molecular genética de algo entonces se entiende y, por tanto, se puede arreglar, aunque no haya ninguna prueba”. Ella quiere aislar a los científicos que financia la fundación de la presión cultural para hacer investigación que lleve rápidamente a resultados publicables, y darles tiempo "para hacer preguntas importantes, ser cuidadosos en lo que hacen y escépticos ante sus propios resultados". Un proyecto en marcha busca sobrevivientes, durante muchos años, de cáncer cerebral maligno para ver cómo interactúan sus tumores con el resto del cuerpo y otras influencias ambientales. ¿Por qué las técnicas de tratamiento que son ineficaces para la mayoría de los pacientes muestran resultados positivos para muy pocos? Es un problema que vincula el desempeño tecnológico con el adelanto científico; el punto ideal para la investigación fundamental.

Pero Fitzpatrick también se pregunta si la ciencia biomédica subestima otros tipos de investigación que podrían ofrecer soluciones a problemas urgentes.

No hay mucha investigación sobre la mejor manera de apoyar social, emocional y ambientalmente a los pacientes de Alzheimer, que alivie su ansiedad y su estrés; quizá la enfermedad, por horrible que sea, sería menos terrible con una mejor estructura de atención, pero hacemos muy poca investigación sobre ese aspecto. 
Quizá por ahora la investigación para ayudar a las personas que tienen estas enfermedades deba apuntar a preguntas más prácticas. "No creo que se pueda decirles 'Bien, tenemos que dedicar otros cuarenta años a la investigación' cuando tampoco sabemos si hay mejores maneras de apoyarlas". Y tal vez en el proceso de entender cómo ayudar mejor a los pacientes, los científicos descubran cosas sobre el curso de la enfermedad y sus variedades que pueden llevar a terapias efectivas. "Lo que se ha perdido es el continuo toma y daca entre la ciencia y la enfermedad real" que ha sido históricamente la fuente de grandes avances médicos.

Siguiendo su propia lógica, gran parte de la ciencia ha perdido de vista el mundo mejor que supuestamente ayuda a crear. Eximido de responsabilidad con cualquier cosa aparte de sí mismo, el "libre juego de intelectos libres" empieza a parecer un simple encubrimiento de la indiferencia y la irresponsabilidad. La ironía trágica es que la atrofiada imaginación de la ciencia predominante es una consecuencia de la autonomía que según los científicos es la clave de su éxito. Solo mediante el compromiso directo con el mundo real la ciencia podrá liberarse a sí misma para redescubrir el camino hacia la verdad. 